"This accepted author manuscript is copyrighted and published by Elsevier. It is posted here by agreement between Elsevier and MTA. The definitive version of the text was subsequently published in [COLLOIDS AND SURFACES B-BIOINTERFACES 135: 225-234 (2015), DOI:10.1016/j.colsurfb.2015.07.066]. Available under license CC-BY-NC-ND." 


\title{
Physicochemical characterization of artificial nanoerythrosomes derived from erythrocyte ghost membranes
}

Róbert Deák $^{\mathrm{a}}$, Judith Mihály ${ }^{\mathrm{a}}$, Imola Cs. Szigyártóa ${ }^{\mathrm{a}}$ András Wacha ${ }^{\mathrm{a}}$, Gábor Lelkes ${ }^{\mathrm{b}}$, Attila Bóta $^{\text {a; } \#}$

${ }^{a}$ Research Centre for Natural Sciences, Hungarian Academy of Sciences, Institute of Materials and Environmental Chemistry, Research Group of Biological Nanochemistry, 1117 Budapest, Magyar tudósok körútja 2, Hungary

${ }^{\mathrm{b}}$ Central Laboratory of the National Institute of Rheumatology and Physiotherapy, 1023 Budapest, Frankel Leó u. 25-29, Hungary

${ }^{\#}$ Corresponding author, bota.attila@ttk.mta.hu

keywords: erythrocyte, vesicles, nanoerythrosomes, small angle x-ray scattering (SAXS), infrared spectroscopy, freeze fracture TEM, protein to lipid ratio

\begin{abstract}
Colloidal stabile nanoerythrosomes with $200 \mathrm{~nm}$ average diameter were formed from hemoglobin-free erythrocyte ghost membrane via sonication and membrane extrusion. The incorporation of extra lipid (1,2-dipalmitoyl-sn-glycero-3-phosphocholine, DPPC), added to the sonicated ghosts, caused significant changes in the thermotropic character of the original membranes. As a result of the increased DPPC ratio the chain melting of the hydrated DPPC system and the characteristic small angle X-ray scattering (SAXS) of the lipid bilayers appeared. Significant morphological changes were followed by transmission electron microscopy combined with freeze fracture method (FF-TEM). After the ultrasonic treatment the large entities of erythrocyte ghosts transformed into nearly spherical nanoerythrosomes with diameters between 100-300 $\mathrm{nm}$ and at the same time a great number of 10-30 nm large membrane proteins or protein clusters were dispersed in the aqueous medium. The infrared spectroscopy (FT-IR) pointed out, that the sonication did not cause changes in the secondary structures of the membrane proteins under our preparation conditions. About fivefold of extra lipid - compared to the lipid content of the original membrane - caused homogeneous dispersion of nanoerythrosomes however the shape of the vesicles was not uniform. After the addition of about tenfold of DPPC, monoform and monodisperse nanoerythrosomes became typical. The outer surfaces of these roughly spherical objects were frequently polygonal, consisting of a net of pentagons and hexagons..
\end{abstract}




\section{Introduction}

Cell membranes and cell membrane derived vesicles are an increasing field of interest, considering studies of composition, morphology, and membrane interactions for the better understanding of physiological and pathological processes and therapeutic possibilities [1-4]. Because of the complex and variable composition of biological membranes, they are often substituted with model membranes for primal investigations. Such model membranes can be simple or more complex artificial lipid bilayers, or even purified membranes prepared from live cells [5-7].

For such purposes, the most commonly used cells are the red blood cells, or erythrocytes. As these lose most of their intracellular membrane components during the maturing process, they are ideal subjects for examinations, and become good starting material for hemolytic membrane preparation as well. Because of their simple intracellular structure the cells and the precipitated cell membranes have only a small amount of cytoplasmic contaminants - such as hemoglobin -, which have to be removed [8].

Numerous studies show, that erythrocytes can be used as vehicles for bioactive agents, therapeutics can be loaded into the cells, or coupled onto their surfaces [9-11]. The advantage of this approach is that they are of natural origin, thereby serving as biocompatible carriers. There are a few different techniques for erythrocyte carrier preparation. The most common way is to use directly the cell as a carrier, because red blood cells are naturally designed vascular carriers with prolonged lifetime and safe elimination process [12-13]. Another possibility is to use the empty ghost membranes [14]. The positive qualities of inorganic and organic carriers can be combined with further processing, e.g. by covering the surfaces of polymer nanocarriers with ghost membranes [15]. This way a camouflaged nanoparticle with the external properties of an erythrocyte can be achieved, whereas the applicability of the polymer core is retained.

Microvesicles with a diameter of few hundred nanometers can be produced from cells or cell compartment membranes, by using procedures from colloid chemistry and physics: filtration, extrusion, sonication or chemical processes [16-17]. Ghost membranes, purified from red blood cells, is an ideal starting material for vesicle preparation because of the simple internal structure of the originating cells. The composition and properties of the resulting nanoerythrosomes are comparable to the original cell membrane [18-19].

In this study we present a novel nanoerythrosome system, produced from erythrocyte ghost membrane with additional lipid, by consecutive extrusion and sonication. The proposed system is assumed to be a step forward from the synthetic liposomes to the natural, cellderived microvesicles. Considering this we highlight the colloid chemical properties of the vesicles with techniques that already play an important role in the examination of artificial nanomaterials, and have a strong potential for the future characterization of natural microvesicles as well. 


\section{Materials and methods}

\section{Chemicals}

Physiological salt solution ( $9 \mathrm{~g} \mathrm{NaCl}$ in $991 \mathrm{~g}$ millipore water), lysis buffer $(7.5 \mathrm{mM}$ TRIS/HCl, pH: 7.6), isotonic PBS buffer solution, analytical reagent-grade ferric chloride, ammonium thiocyanate and Bradford reagent were purchased from Sigma Aldrich. Bovine Serum Albumin standard was supplied by Bio-Rad Hungary Ltd.

1,2-Dipalmitoyl-sn-glycero-3-phosphocholine (DPPC) was obtained from NOF America Corporation (USA).

Red blood cells were isolated from the blood of healthy volunteers, collected at the Central Laboratory of the National Institute of Rheumatology and Physiotherapy, Budapest, Hungary. The ghost membrane preparation was performed at the Research Centre for Natural Sciences, Hungarian Academy of Sciences.

\section{Ghost membrane and nanoerythrosome preparation}

For membrane preparation $25 \mathrm{ml}$ of citrated blood was used. All steps of isolation were performed at $4^{\circ} \mathrm{C}$.

Red blood cells were isolated with a NÜVE NF 800R centrifuge at $4100 \mathrm{rpm}$, and were washed several times with physiological salt solution until the platelets and the buffy coat was completely removed. The pure erythrocytes were lysed in $40 \times$ volume lysis buffer. The empty membranes were washed three times with an Avanti J26XP centrifuge, $10000 \mathrm{rpm}$, to achieve hemoglobin free ghosts. The final ghost pellet was suspended in isotonic PBS buffer.

The hemoglobin free ghost membrane suspension was the starting material for the further microvesicle preparation. To use it as a homogeneous stock solution (N1) it was diluted with PBS and was treated with a Biologics INC ultrasonic homogenizer for 5 minutes, $10 \%$ power, $50 \%$ pulser. Nanoerythrosomes were made from the stock solution by consecutive sonication and extrusion through a $200 \mathrm{~nm}$ pore size polycarbonate membrane, using an Avanti Mini-Extruder.

The total amount of ghost membrane dry material was determined by a gentle drying process. $10 \mu \mathrm{l}$ of homogenized, sonicated ghost suspension was pipetted on a silicate plate. After complete drying its weight was measured with analytical balance.

From the ghost membrane suspension (N1), vesicles with three different lipid compositions were prepared (for the preparation protocol see Suppl.1.). The first sample N2 was without any additive, just the N1 ghost membrane, followed by extrusion. The next two samples were diluted with additional phospholipid (DPPC), approximately fivefold ( $3 \mathrm{mg}$, $\mathrm{N} 3$ ) and tenfold (6 mg, N4) of its original lipid amount, which was estimated - according to literature ratios [1] -, from the weight measurements via analytical balance. N3 and N4 vesicles were prepared via an additional sonication step, followed by extrusion.

Vesicle preparations and measurements were carried out three times, from three independent isolations.

\section{Differential scanning calorimetry (DSC)}

A $\mu$ DSC 3 EVO (Setaram, France) apparatus was used for calorimetric experiments. Each time approximately $10 \mathrm{mg}$ sample was used, the reference was an empty sample holder. The heating protocol consisted of three cycles, from $20^{\circ} \mathrm{C}$ to $60^{\circ} \mathrm{C}$ and cooling back, with two different scan rates, first a faster $1^{\circ} \mathrm{C} / \mathrm{min}$ and then a slower $0.5^{\circ} \mathrm{C} / \mathrm{min}$ for better resolution. The results are presented from the latter. 


\section{Transmission electron microscopy combined with freeze fracture (FF-TEM)}

Approximately $1 \mu \mathrm{l}$ droplets of the samples were used for freeze fracturing. The samples were pipetted onto a golden sample holder and rapidly frozen in liquid freon, then put into liquid nitrogen. Fracturing was performed at $-100^{\circ} \mathrm{C}$ in a Balzers freeze-fracture device (Balzers BAF 400D, Balzers AG, Liechtenstein). A replica was made from the fractured surface with vaporized carbon-platinum. The replica was washed with surfactant solution and distilled water, and it was transferred to 200 mesh copper grid for transmission electron microscopic (MORGAGNI 268D, FEI, The Netherlands) examination.

\section{Small angle $x$-ray scattering (SAXS)}

Small-angle X-ray scattering measurements [20-22] were performed using CREDO, an in-house transmission geometry set-up [23]. Samples were filled into thin-walled quartz capillaries of $1.2 \mathrm{~mm}$ average outer diameter. After proper sealing, these were placed in a temperature controlled aluminum block, which was inserted into the vacuum space of the sample chamber. Measurements were done using monochromatized and collimated $\mathrm{Cu} \mathrm{K \alpha}$ radiation $(0.1542 \mathrm{~nm}$ wavelength), and the scattering pattern was recorded in the range of $0.23-1.03 \mathrm{~nm}^{-1}$ in terms of the scattering variable, $q(q=4 \pi \sin \theta / \lambda$, where $2 \theta$ is the scattering angle and $\lambda$ is the X-ray wavelength). The total measurement time was 7.5 hours for each sample. In order to be able to assess sample and instrument stability during the experiment, the exposures were made in 5 minute units, with frequent sample change and reference measurements. These individual exposures were corrected for beam flux, geometric effects, sample self absorption and instrumental background, as well as calibrated into physical units of momentum transfer $\left(q, \mathrm{~nm}^{-1}\right)$ and differential scattering cross-section (absolute intensity, $\left.\mathrm{cm}^{-1} \times \mathrm{Sr}^{-1}\right)$. The average of the corrected and calibrated 5 minute scattering patterns was azimuthally averaged to yield a single one-dimensional scattering curve for each sample.

\section{Fourier transform infrared spectroscopy (FT-IR)}

FT-IR spectroscopic measurements were carried out by means of a FT-IR spectrometer (Varian 2000, Scimitar Series, United States), fitted with a diamond attenuated total reflection cell ('Golden Gate' single reflection ATR unit with active area of $600 \times 600$ $\mu \mathrm{m}^{2}$, Specac, United Kingdom). $5 \mu$ of sample was spread onto the diamond ATR surface and a thin dry film was obtained by slowly evaporating the solvent under ambient conditions ( approx. $5 \mathrm{~min}$ ). The second derivatives of the measured spectra were obtained by the Savitsky-Golay method (third order polynomial, 5 smoothing points).

For temperature controlled measurements a home-made liquid cell with volatile solvent cover was applied; the temperature was equilibrated for $5 \mathrm{~min}$ before collection of each spectrum. Typically, 64 scans were collected at a nominal resolution of $2 \mathrm{~cm}^{-1}$. After each data acquisition, ATR correction (and water background spectral subtraction) was performed. The actual frequencies of complex IR bands were determined by fitting their peaks with Lorentzian curves. For all spectral manipulation the Grams/32 software package (Galactic Inc., USA) was used.

\section{Ultraviolet and Visible Spectroscopy (UV-Vis)}

All UV-Vis measurements were done at $25^{\circ} \mathrm{C}$ using an 8453 diode array UV-Vis spectrophotometer (Hewlett-Packard, USA) thermostated with Grant LTD 6G circulating water bath, in a quartz cuvette with a $1 \mathrm{~cm}$ optical path.

\section{Colorimetric assay procedures}


The Stewart assay was used to measure the total lipid content of the nanoerythrosome systems, where the ability of phospholipids to form a complex with ammonium ferrothiocyanate in chloroform solution is utilized. Lipid standard solution $(0.1 \mathrm{mg} / \mathrm{ml})$ was prepared from Brain Total Lipid Extract (from Avanti Polar Lipids Inc.) in chloroform. The assay was carried out in Eppendorf tubes containing $1 \mathrm{ml}, 0.1 \mathrm{M}$ ammonium ferrothiocyanate solution, different volumes of the lipid standard solution $(0-0.5 \mathrm{ml})$, and the required quantity of chloroform up to a final volume of $2 \mathrm{ml}$. The systems were vortexed and shaken vigorously for 10 minutes, followed by centrifugation $(10 \mathrm{~min})$ at $1200 \mathrm{~g}$ at room temperature. The lower layer was removed and placed into a quartz cuvette. The absorbance was measured at $485 \mathrm{~nm}$. A similar procedure was used for sample solutions.

The total protein content of ghost vesicle samples was determined using the Bradford assay that involves the binding of Coomassie Brilliant Blue G-250 dye to proteins. Bovine Serum Albumin was used as standard. To $0.5 \mathrm{ml}$ of each standard $(0-25 \mu \mathrm{g} / \mathrm{ml})$ and unknown sample solution were added $0.5 \mathrm{ml}$ dye reagent and was vortexed for $15 \mathrm{sec}$. The samples were incubated at room temperature for at least $5 \mathrm{~min}$ and the absorbance was measured at $595 \mathrm{~nm}$.

\section{Dynamic light scattering (DLS)}

A W130 dynamic light scattering apparatus (AvidNano, United Kingdom) was used for measuring the average size and size distribution of the samples. Because of the small sample volumes a $50 \mu \mathrm{l}$ microcuvette was suitable. The analysis of the measurement data was performed with the i-Size software, supplied with the apparatus.

\section{Zeta potential measurement}

Stability of nanoerythrosome samples was assessed by zeta potential measurements using a Malvern Zetasizer Nano ZS (Malvern Instruments Ltd, United Kingdom) instrument. The samples, originally in PBS, were diluted to 50× volume with ultrapure (MilliQ) water, in order to make the surface characteristics of the vesicles measurable. 


\section{Results and discussion}

\section{Calorimetric experiments}

In contrast with pure hydrated lipid systems, biological membranes, such as cell membranes or nanoerythrosomes do not undergo significant first order phase transitions in the biologically relevant temperature interval between $30^{\circ} \mathrm{C}$ and $50^{\circ} \mathrm{C}$ (Fig.1.) [24]. The complexity of real membranes inhibits the formation of homogeneous domains composed of the same constituent (e.g. lipids, proteins, carbohydrates etc.) where temperature induced characteristic structural changes can occur. This lack of phase transitions is the cause of the monotonously changing signal observed in the thermogram of the sonicated, extruded ghost membrane in Fig.1. In the presence of additional DPPC well expressed phase transition signals appear. As the amount of additional lipid is increased in the nanoerythrosomes, the transition signal becomes more expressed and the temperature of transition approaches the characteristic value of the hydrated pure lipid system.

If we take a closer look at the measurement data shown in Fig.1. and also Suppl.5., the effects of the lipid enrichment can be followed. In the sample with the lower amount of extra DPPC (N3) the enthalpy change relative to one mole of added lipid is significant, but its value $(3.7 \mathrm{~kJ} / \mathrm{mol})$ is about 10 percent of that of the pure lipid system. This minor change in enthalpy indicates the good miscibility of DPPC with the erythrocyte membrane constituents. Twice as much added lipid results in a further, more significant increase of enthalpy change $(9.7 \mathrm{~kJ} / \mathrm{mol})$ in the $\mathrm{N} 4$ sample, indicating the further enrichment of lipid domains with DPPC. The shape of the transition signal is also altered: the higher the DPPC ratio, the sharper the endothermic transition peak is. From the broadening of the peaks the cooperativity of the chain melting of the lipid domains can be deduced: the width is inversely proportional to the number of the molecules melting simultaneously [25,26]. Moreover, the characteristic melting point of nanoerythrosomes increases from 39.5 to $40.1^{\circ} \mathrm{C}$, almost to $41.5^{\circ} \mathrm{C}$, measurable in the case of a pure, fully hydrated DPPC system.

These findings show the presence of DPPC guest molecules change the shape of the DSC curve into a form which reflects the characteristics of the phase transitions of DPPC, although the complete thermotropic character of the pure hydrated lipid system cannot be observed. In this temperature interval the pure and fully hydrated DPPC system undergoes two transitions which are the pretransition (approximately at $34^{\circ} \mathrm{C}, 7.8 \mathrm{~kJ} / \mathrm{mol}$ ) and the chain melting (known as main transition, at $41.5^{\circ} \mathrm{C}, 37 \mathrm{~kJ} / \mathrm{mol}$ ) [27]. In our case the pretransition cannot be observed despite the large amount of the aforementioned lipid. This indicates that the head-group regions of the lipid domains might be influenced by other molecules originating from the ghosts. This deviation from the characteristic calorimetric data of the pure lipid system suggests that the supplementary lipids get embedded in the membrane and do not create independent colloidal formations, entirely separated from the erythrosomes.

\section{Transmission electron microscopy}

Freeze fracture electron microscopy provides an excellent possibility to visualize the hydrophobic center of the nanoerythrosome membranes. Some typical electron micrographs are shown in Figs. 2-3. Each sample exhibits different characteristic morphology.

Freshly prepared ghost membranes are large sheets, their lateral size is about $2-4 \mu \mathrm{m}$, as it can be seen from Fig. 2. Their fracture surfaces are randomly speckled with intramembrane particles which represent integral membrane proteins. The typically convex inner half of the bilayer (the so-called $\mathrm{P}$ face) contains more, while the concave outer half (E face) shows much less of these particles (Fig.2.A3. and Fig.2.A2.). The typical size of these particles is less than $10 \mathrm{~nm}$. 
After ultrasonic homogenization the morphology undergoes a drastic change, as instead of heterodisperse, large, irregular formations, nearly spherical small nanoerythrosomes are formed in the N2 sample. Surprisingly, their diameter falls into a relatively narrow size range between $100-200 \mathrm{~nm}$ (the size distribution of the sonicated ghost membrane, N2 is shown in the Suppl.2.). Both fracture faces of the nanoerythrosomes contain particles which are frequently aggregated (Fig.2.B1-2 and B4.). In addition to these observations, a significant amount of particulate matter was seen between the nanoerythrosomes (marked by arrows on the inset of Fig.2.B2.). The size of these particles falls in the range of $10-30 \mathrm{~nm}$. These are presumably transmembrane proteins or protein clusters with their lipid surroundings, which left the ghost membrane in the course of the ultrasound treatment. Because of their relatively small size compared to the whole nanoerythrosomes, they cannot be detected by DLS. They are also invisible for SAXS, but for a different reason.

For the purpose of providing a homogeneous dispersion of small, protein containing vesicles, additional DPPC was mixed to the suspension. Another sonication step was applied, which was followed by extrusion through a $200 \mathrm{~nm}$ filter with the hope that protein aggregates and vesicles with unfavorably high protein content will rearrange into a more uniform distribution.

The addition of lipid molecules caused further changes in the surface morphology. The number of small entities between the nanoerythrosomes decreased significantly, and at the same time, nanoerythrosomes appear more frequently than without the extra DPPC, as it can be observed in Fig.3.A. The nanoerythrosomes having extra DPPC are often larger than in the previous case of no excess lipid, but still have a diameter below $200 \mathrm{~nm}$. In the electron micrographs both the convex and concave fracture surfaces appear. The formations, however, are neither spherical nor uniform. Irregular and stumpy-shaped creations are frequently visible. The faces of the nanoerythrosomes are not smooth, but seem to be composed of polygonal objects. In fact, the nanoerythrosomes look polyhedral (Fig.3.A4.). Ridges can frequently be seen between the faces of the polyhedral, and these seem to be composed of particles (Fig.3.B4.) From these ridges an extended network is made up on the nanoerythrosomes. Presumably the proteins/protein aggregates connect to each other, forming a wireframe covering the nanoerythrosomes. In this network frame different, occasionally regular, polygons are visible.

After doubling the amount of added DPPC the nanoerythrosomes become more monodisperse and monoform, as shown in Fig.3.B. The spherical forms become typical and other aggregations are hardly observable. The formation of the polygonal frame results typically in pentagons and hexagons. The morphology of these units is very similar to that of clathrin-coated vesicles [28].

\section{Small-angle $X$-ray scattering}

Significant changes can be observed in the small-angle X-ray scattering (SAXS) of the ghost membranes due to the presence of excess DPPC, as shown in the cases of sonicated ghost membranes without (N2) and with (N3, N4) DPPC in Fig.4. In all of the three samples an intense, monotonously decreasing scattering appears in the beginning range of the scattering variable, which follows a power-law in the case of $\mathrm{N} 3$ and $\mathrm{N} 4$, but to a very small extent in $\mathrm{N} 2$ as well. This is the Porod-range of objects in the size range from several tens up to hundreds of nanometers. Such objects include the nanoerythrosomes themselves, proteins and/or their aggregates, as well as the $10-30 \mathrm{~nm}$ protein/lipid clusters found by freeze-fracture transmission electron microscopy. Suppl. 6. gives a simple explanation of the shape of N2 in terms of a measured scattering curve of a unilamellar vesicle and an added power-law contribution from larger objects. 
The scattering curve of the sonicated and extruded ghost membrane system (N2) is less characteristic, lacking all signs of a defined layer structure. Upon adding DPPC to the system (samples N3 and N4) however, a well expressed, broad peak appears in the scattering curve in the interval from 0.8 to $2 \mathrm{~nm}^{-1}$, which corresponds to the squared form factor of a single phospholipid bilayer in a unilamellar vesicle [29-31]. Its appearance is squarely indicative of the presence of lipid bilayers, thus the dominant structural features are due to the extra DPPC molecules. In N4 the increased amount of DPPC results in a more pronounced peak, indicating a change in the composition of the nanoerythrosome layers.

Considering the visual information obtained by the freeze-fracture method we can suppose that the scatterers are nearly spherical, unilamellar formations. Although their shells are not homogeneous, a spherical shell structure, as a crude model can quantify the shape of the scattering curve of the nanoerythrosomes loaded with DPPC. In other words, a structural analogy between nanoerythrosomes and sterically stabilized unilamellar vesicles is assumed. By employing a shell model of spherical symmetry, an approximate description of the layer structure becomes feasible in terms of the radial electron density distribution. Neglecting the interactions between individual nanoerythrosomes and assuming spherical symmetry, the scattering intensity can be calculated by the symmetric '2 Gaussian' model [31-34]. Here one pair of Gaussian functions represent the variation of electron density orthogonal to the bilayer surface due to the polar head group regions, while another pair describes the protein molecules located in the bilayer and at its both surfaces. Although it is not reflected in the name of the model, a third, single Gaussian contribution is also used to describe the hydrocarbon chain region of the lipid double layers. To reduce the number of independent parameters in the model and to aid its convergence to a physically relevant result, the parameters describing the head groups and the chain region were assumed to be the same as of a pure DPPC bilayer and only the Gaussians for protein localization were fitted. Even though this model might be overly simplistic, the best fit of the N4 system indicates asymmetric protein localization in the erythrosomes. It shows that the membrane proteins are mainly located in the bilayer and on its outer leaflet. The layer thickness, approximated to be about $11 \mathrm{~nm}$, is significantly larger than that of the hydrated pure DPPC bilayer as it is demonstrated in Fig.5.

\section{FT-IR Spectroscopy}

Dry film spectra of ghost vesicles recorded at $25^{\circ} \mathrm{C}$ are presented in Fig.6. The spectrum of the sonicated and extruded erythrocyte ghost vesicles (N2) shows typical features of biological samples: the stretching vibrations of lipid hydrocarbon chain moiety with a little contribution of $-\mathrm{CH}_{3}$ groups of protein side chains (at 3050-2700 $\mathrm{cm}^{-1}$ ), carbonyl esters (at $1738 \mathrm{~cm}^{-1}$ ) and the Amide I and Amide II modes of protein peptide bonds at 1656 and 1542 $\mathrm{cm}^{-1}$, respectively [35]. As additional DPPC is mixed to the ghost vesicle samples, the intensity of the characteristic stretching bands of $\mathrm{CH}_{2}$ and $\mathrm{C}=\mathrm{O}$ groups, related to lipid entities, increases accordingly (see N3 and N4 in Fig.6.; for better visualisation all spectra are normalised to the protein Amide I band).

Protein secondary structure and estimation of protein to lipid ratio: changes in protein content and structure

The Amide I and Amide II bands are the two major bands of the proteins. The Amide I is mainly determined by the stretching vibrations of the $\mathrm{C}=\mathrm{O}(70-85 \%)$ and bending of $\mathrm{N}-\mathrm{H}$ groups (10-20\%) and its shape and band position is directly related to the backbone conformation and $\mathrm{H}$-bonding pattern. The most common techniques used to determine secondary structure composition of proteins is the analysis of the second derivative of the Amide I region (Suppl.7.). For both the native ghost membrane (N1) and all ghost vesicle 
samples (N2, N3 and N4), the main component of Amide I is at $1657 \mathrm{~cm}^{-1}$, corresponding to $\alpha$-helix structure with a small content of $\beta$-sheet $\left(1633,1682 \mathrm{~cm}^{-1}\right)$ and irregular structure $\left(1611 \mathrm{~cm}^{-1}\right)[36]$ indicating that no protein aggregation/degradation occurs during sonication under our preparation conditions (Suppl.7.). As to the ghost vesicles (N2) the peak position of Amide I has been slightly shifted towards higher wavenumber, as a consequence of possible changes in the lipid environment. After DPPC addition, however, this slight shift is recovered. FT-IR spectroscopy can also be used to estimate protein to lipid ratio value: we used the Amide I to integrated $\mathrm{CH}_{2}$ stretching bands $\left(3020-2700 \mathrm{~cm}^{-1}\right)$ intensity ratio to compare the relative amounts of the proteinic and lipidic components. The estimated spectrum-based protein to lipid value decreases drastically by the addition of increasing amount of DPPC (see Table 1.).

\section{Analysis of the C-H stretching region: lipid disorder}

The C-H stretching region of the IR spectra $\left(3020-2700 \mathrm{~cm}^{-1}\right)$ involves mostly the fatty acyl chains of the membrane lipids. As to the biological sample (N2), the antisymmetric $\left(v_{\mathrm{as}} \mathrm{CH}_{2}\right)$ and symmetric $\left(\mathrm{v}_{\mathrm{s}} \mathrm{CH}_{2}\right)$ methylene vibrations exhibit relatively high wavenumbers (2923 and $2853 \mathrm{~cm}^{-1}$, respectively) suggesting a high lipid disorder in the ghost membranes (containing increased amount of 'gauche' segments, typical for biological samples with membrane lipids in liquid-crystalline state) [37]. Moreover, the olefinic $=\mathrm{CH}$ stretching band of unsaturated membrane lipids can also be witnessed (at $3012 \mathrm{~cm}^{-1}$, not shown). By addition of DPPC, however, the position of $v_{\mathrm{as}} \mathrm{CH}_{2}$ and $v_{\mathrm{s}} \mathrm{CH}_{2}$ coincide with that of pure DPPC (2918 and $2850 \mathrm{~cm}^{-1}$, respectively) [38]. This observation suggests that added DPPC forms domains or rafts rich in pure synthetic lipid. Once in their own phase, these lipids may form domains in which they are less disordered than they were at the protein-lipid interface.

The formation of DPPC-rich rafts is further confirmed by investigating the thermotropic responses of $v_{\mathrm{s}} \mathrm{CH}_{2}$ for $\mathrm{N} 3$ and $\mathrm{N} 4$ vesicles (Fig.7.). The abrupt increase in the peak frequency of the symmetric $\mathrm{CH}_{2}$ stretching mode is due to the change from trans to gauche conformers of lipid acyl chains during the main endothermic phase transition, i.e. a higher gauche segment population [39]. The temperature dependence of pure DPPC liposomes exhibits a sharp transition from gel to liquid-crystalline phase with a $\mathrm{T}_{m}$ around 41$42^{\circ} \mathrm{C}$ (in accordance with DSC measurements). For the ghost-derived sample (N3), this phase transition is broadened with a lower starting phase transition temperature. Increasing the amount of additional DPPC the slope of the curve resembles more that of pure DPPC, suggesting the formation of domains of 'pure' lipids. However, for all ghost-derived nanocarriers the proportion of the gauche isomers of acyl chains is lower with respect to the pure lipid (DPPC). It seems plausible that the additional DPPC incorporates as pure lipid domains/rafts into the ghost membrane structure and the thermotropic response of these are constrained by the lipid/ghost constituent interaction.

\section{Spectrophotometric quantification of phospholipids and proteins in ghost samples}

There are several reviews in the literature on the protein and lipid content of the erythrocyte membrane. Approximately $52 \%$ of the membrane mass is protein, $40 \%$ is lipid and $8 \%$ is carbohydrate [40]. Furthermore, there is a great variability in the measured protein and lipid content of the human red blood cell plasma membrane, from $40 \%$ protein and $35 \%$ lipid to $20 \%$ and $70 \%$ content, respectively $[1,41]$.

For all nanoerythrosome samples (N2, N3 and N4) Bradford and Stewart assays were used to estimate the protein and lipid quantities.

Protein concentration in samples was calculated on the basis of a standard curve, prepared with known amount of bovine serum albumin and the absorbance was measured at $595 \mathrm{~nm}$. Protein content of the native ghost membrane was found to be $0.929 \mathrm{mg} / \mathrm{ml}$. As 
shown by Table 1. and Suppl.8., a loss of protein could be observed due to the extrusion procedure.

Phospholipids form a colored complex with ammonium ferrothiocyanate in chloroform solution (absorbance read at $485 \mathrm{~nm}$ ). Lipid concentration was calculated using the standard curve prepared from Brain Total Lipid Extract. Total Lipid Extract is a chloroform-methanol extract of porcine brain, heart, etc. tissues and of soybean, containing 9.6wt/wt\% PC; $16.7 \%$ PE; $1.6 \%$ PI; $10.6 \%$ PS; $2.8 \%$ PA and $58.7 \%$ unknown component. This extract is partitioned against deionized water and the chloroform phase is concentrated.

The lipid content of nanoerythrosome vesicles was found to be proportional to the amount of additional DPPC. As the amount of extra DPPC is raised the measured protein/lipid ratios of different analytical procedures give more and more similar results (Table 1.). 


\section{Conclusion}

Erythrocyte membrane is a widely studied biomaterial due to its envisaged medical, biochemical and pharmaceutical applications [1,2,5,8]. Several studies revealed primal properties of their bilayer concerning its average structure, composition as well as the asymmetric distribution of their lipid and protein content $[1,5]$. As far as membrane proteins are concerned, according to the literature they can be classified into two major groups, depending on how easily they can be removed from the surface. Some of them can be washed out without using any harsh reagents, as they are weakly attached and only to the inner side of the membrane, while others are strongly embedded into- or permeated through the lipid bilayer which makes them difficult to remove. The latter are called integrated proteins (e.g. band-3, or glycophorin) and the previous are the peripheral proteins (e.g. spectrin) [1].

\section{The ghost membrane}

During the ghost membrane preparation process, the applied centrifugations and lysis buffer dilutions washed out most of the peripheral proteins, while the adjustment of $\mathrm{pH}$ and low temperature helped preserving the amount and quality of integral proteins. TEM images of ghosts N1 (Fig.2.A) reveal a large number of homogeneously distributed integral proteins on the membrane surface which serves as a quality control of the stock solution before further processing [8].

\section{Vesicle preparation from erythrocyte ghosts}

Physicochemical treatment in the N2 sample caused the vesicularisation of the ghost membranes, resulting in two major groups of components: vesicles, with a diameter of approximately $100 \mathrm{~nm}$, and free particles of approximately $10 \mathrm{~nm}$ (Fig.2.B). It is assumed that when vesicles are formed from the large membranes, part of its trans-membrane protein content is released because of the impacts of sonication and extrusion. We assume that these released proteins form the fraction of observed smaller components. As these components are significantly larger than the particles seen in ghost membranes (N1), it is believed that they are surrounded by part of their original lipid environment and likely to be aggregated.

The signal of these out-of-membrane proteins occurs in FT-IR (Suppl.7.) and on FFTEM images (Fig.2.B2.). In the FT-IR spectrum of N2 a slight shift of the proteins' Amide I band peak can be observed. This shift suggests environmental changes of the molecules rather than conformational changes, which shows that they are likely to be torn out from their original membrane milieu. Moreover, the shape of the SAXS curve of N2 can be interpreted as a sum of the scattering of unilamellar vesicles, and the scattering of small particles, such as the out-of-membrane proteins (Suppl.6.).

\section{Improvement of vesicle properties with lipid addition}

In previous studies on cell membranes, asymmetric lipid distribution and exchange between membrane lipids and their milieu were presented [42, 43]. These phenomena confirmed the possibility of artificial lipid incorporation into the erythrocyte ghosts.

For the purpose of providing a homogeneous dispersion of small, protein containing vesicles from sample N2, additional DPPC was mixed to the suspension, followed by sonication and extrusion. DPPC is a commonly used, typical outer membrane phospholipid of human erythrocytes. This extra lipid, with the help of the applied physicochemical treatments rearranged the previously heterodisperse particles into a more uniform vesicle distribution. The TEM images of sample N3 (Fig.3.A) reveal that there are no longer out-of-membrane 
particles, while a more homogeneous new type of vesicles appeared. On the surface of these vesicles a network-like morphology can be seen, which is likely to be a result of the incorporated, previously out-of-membrane proteins and the rearranged membrane proteins of the smaller vesicles of N2. It is believed that the frame of this grid network is formed by the proteins, and the facets in between are filled with the additional phospholipid.

Just like in the case of the original ghost samples, in FT-IR a shift of the Amide I band towards lower wavenumbers confirms the incorporation of out-of-membrane particles into the N3 vesicles (Suppl.7.).

\section{Further lipid addition leads to more homogeneous samples}

Although the small, out-of-membrane particles were incorporated into the rearranged vesicles by the additional lipid in sample N3, the newly formed vesicles were still quite heterodisperse. Stumpy shaped and aggregated formations were often seen (Fig.3.A2; A3.), which are believed to be the results of the rigid protein frame. Raising the amount of additional DPPC had some positive consequences on the vesicles' morphology. In the N4 samples with more extra phospholipid, monoform, nearly spherical vesicles were created (Fig.3.B). The average size of these vesicles is slightly, but significantly larger than the ones in N3 (Suppl.2; Fig.3.B). The protein frame on their surface is even more spectacular, with the appearance of polygonal shapes. This suggests that with the addition of even more lipid the protein frame became dilated, consequently the lipid rich domains between them got larger.

DSC curves (Fig.1.) and the results of temperature-dependent FT-IR measurements (Fig.7.) confirm the incorporation of the additional phospholipid into the membranes. Both experiments show that with more extra phospholipid the samples gain properties comparable to pure DPPC vesicles. However the enthalpy changes of the main phase transitions and the thermotropic shifts of the $\mathrm{CH}_{2}$ stretching vibrations never reach the pure DPPC values. The phase transition is always slightly hindered, because of the protein frame that surrounds the lipid islands. This might also be the reason behind the absence of the pretransition, as shown by calorimetric measurements.

\section{The advantage of nanoerythrosomes}

Ideal nanocarriers - under the internal conditions of an organism - should meet many requirements like stability, homodisperse and small size distribution, high loading capacity and specific release sites, long circulation time, biodegradability and biocompatibility.

To achieve the listed structural and morphological properties with synthetic liposomes the conventional technique is sterical stabilization with polymers like poly(ethylene-glycol) (PEG). Currently PEG coated liposomes are the only commercially available stabilized liposomes on the market, although - according to the literature - PEG chains can induce immune response through the formation of anti-PEG antibodies. Consequently these antibodies accelerate the clearance of the liposomes and change their pharmacokinetical properties $[44,45]$. As a result, replacing PEG with more biocompatible molecules would be favorable. This is one reason behind (re)discovering bio-originated vesicles. Using cell membranes and membrane derived vesicles such as microvesicles and exosomes would provide naturally stabile, biocompatible and potentially targeted nanocarriers built by Mother Nature. While they seem to be ideal starting materials, they also need further development regarding their applicability, as it is problematic to isolate microvesicles in high concentration, while cell membranes have to be further processed before application (e.g. vesicularisation, homogenization). With the preparation of nanoerythrosomes we attempt to 
create a nanocarrier system that combines the biological origin with the high concentration and reproducibility of synthetic liposomes [18].

Nanoerythrosomes are small $\left(\mathrm{d}_{\text {mean }}=200 \mathrm{~nm}\right)$ artificial vesicles, produced from erythrocyte ghost membrane, stabilized naturally by their membrane protein- and carbohydrate components. According to zeta potential measurements (Suppl.4.), they seem to be stabile. Starting from approximately $-42 \mathrm{mV}$ in the case of sample N2, the measured values increase with the amount of extra lipid, but they do not exceed $-20 \mathrm{mV}$ even in the case of $\mathrm{N} 4$ (Suppl.3). Membrane proteins are also good reactive partners for nanocarrier conjugations (e.g. for tracing or marker materials, dyes and also drugs).

To summarize, the advantages of nanoerythrosomes over conventional nanoformulations are their biological origin, their complex, natural membrane composition as a more appropriate model, and carrier system - and their stability without additional synthetic components (e.g. PEG-lipids).

\section{Acknowledgement:}

The authors thank Teréz Kiss for the FF-TEM investigations.

The work was financially supported by the Hungarian Scientific Research Found (OTKA, Hungary), the National Innovation Office (NIH, Hungary) under Grant Agreement CNK-81056, and by MEDinProt Grant of Hungarian Academy of Sciences (A.B.).

The FT-IR spectroscopy part of this work was supported by the János Bolyai Research Scholarship of the Hungarian Academy of Sciences (J.M.). 


\section{References:}

[1.]S. de Oliveira, C. Saldanha: An overview about erythrocyte membrane, Clin. Hemorheology and Microcirculation 44 (2010) 63-74.

[2.]E.M. Pasini, H.U. Lutz, M. Mann, A.W. Thomas: Red blood cell (RBC) membrane proteomics - Part I: Proteomics and RBC physiology, J. of Prot. 73 (2010) 403-420.

[3.]B. György, T.G. Szabó, M. Pásztói, Z. Pál, P. Misják, B. Aradi, V. László, E. Pállinger, E. Pap, A. Kittel, G. Nagy, A. Falus, E. Buzás: Membrane vesicles, current state-of-the-art: emerging role of extracellular vesicles, Cell. Mol. Life Sci. 68 (2011) 2667-88.

[4.]D.S. Choi, D.K. Kim, Y.K. Kim, Y.S. Gho: Proteomics, transcriptomics and lipidomics of exosomes and ectosomes, Proteomics 13 (2013) 1554-1571.

[5.]H. Li, G. Lykotrafitis: Erythrocyte Membrane Model with Explicit Description of the Lipid Bilayer and the Spectrin Network, Biophysical J. 107 (2014) 642-653.

[6.]H.H. Shen, T. Lithgow, L.L. Martin: Reconstitution of Membrane Proteins into Model Membranes: Seeking Better Ways to Retain Protein Activities, Int. J. Mol. Sci. 14 (2013) 1589-1607.

[7.]C. Peetla, A. Stine, V. Labhasetwar: Biophysical interactions with model lipid membranes: applications in drug discovery and drug delivery, Mol. Pharm. 6 (2009): 1264-1276.

[8.]P.P. da Silva: Translational mobility of the membrane intercalated particles of human erythrocyte ghosts $\mathrm{pH}$ dependent, reversible aggregation, The J. of Cell Biol. 58 (1972) 777-787.

[9.]V.R. Muzykantov: Drug delivery by red blood cells: vascular carriers designed by mother nature Expert Opinion Drug Deliv. 7 (2010) 403-427.

[10.] N. Sternberg, R. Georgieva, K. Duft, H. Bäumler: Surface-modified loaded human red blood cells for targeting and delivery of drugs, J. of Microencapsulation., 29 (2012) 9-20.

[11.] I.T. Kostića, V.Lj. Ilićb, V.B. Đorđevića, K.M. Bukaraa, S.B. Mojsilovićb, V.A. Nedovićc, D.S. Bugarskib, Đ.N. Veljovića, D.M. Mišićd, B.M. Bugarski: Erythrocyte membranes from slaughterhouse blood as potential drug vehicles: Isolation by gradual hypotonic hemolysis and biochemical and morphological characterization, Colloids and Surf. B Biointerfaces 122 (2014) 250-259.

[12.] W. Fana, W. Yanb, Z. Xub, H. Nia: Erythrocytes load of low molecular weight chitosan nanoparticles as a potential vascular drug delivery system, Colloids and Surf. B: Biointerfaces 95 (2012) 258- 265.

[13.] G.I. Harisa, M.F. Ibrahim, F.K. Alanazi: Erythrocyte-mediated Delivery of Pravastatin: In Vitro Study of Effect of Hypotonic Lysis on Biochemical Parameters and Loading Efficiency, Archives of Pharmacal Res. 35 (2012) 1431-1439.

[14.] M. Shaillendera, R. Luoa, S.S. Venkatramana, B. Neub: Layer-by-layer microcapsules templated on erythrocyte ghost carriers Int. Journal of Pharmaceutics 415 (2011) 211217.

[15.] C.M.J. Hu, L. Zhang, S. Aryal, C. Cheung, R.H. Fang, L. Zhang: Erythrocyte membrane-camouflaged polymeric nanoparticles as a biomimetic delivery platform, 108 PNAS (2011) 10980-10985.

[16.] R. Shingles, R.E. McCarty: Production of membrane vesicles by extrusion: Size distribution, enzyme activity, and orientation of plasma membrane and chloroplast innerenvelope membrane vesicles, Anal. Biochem. 229 (1995) 92-98.

[17.] S.C. Jang, O.Y. Kim, C.M. Yoon, D.S. Choi, T.Y. Roh, J. Park, J. Nilsson, J. Lötvall, Y.K. Kim, Y.S. Gho: Bioinspired Exosome-Mimetic Nanovesicles for Targeted Delivery of Chemotherapeutics to Malignant Tumors, ACS Nano, 7 (2013) 7698-7710. 
[18.] N. Banerjee, S. Singh: Nanoerythrosomes - Dawn of a new era in Carrier Mediated Targeted Drug Delivery, Int. J. of Res. in Pharmaceutical and Biomedical Sciences 4 (2013) 436-455.

[19.] R. Pouliot, A. Saint-Laurent, C. Chypre, R. Audet, I. Vitté-Mony, R.C. Gaudreault, M. Auger: Spectroscopic characterization of nanoErythrosomes in the absence and presence of conjugated polyethyleneglycols: an FTIR and 31P-NMR study, Biochimica et Biophysica Acta 1564 (2002) 317- 324.

[20.] L.A. Feigin, D.I. Svergun: Structure Analysis by Small-Angle X-Ray and Neutron Scattering (New York: Plenum Press) (1987)

[21.] O. Glatter, O. Kratky: Small angle x-ray scattering (New York: Academic Press) (1982)

[22.] A. Guinier, G Fournet: Small-angle scattering of X-rays (New York: John Wiley \& Sons, Inc.) (1955)

[23.] A. Wacha, Z. Varga, A. Bóta: CREDO: a new general-purpose laboratory instrument for small-angle X-ray scattering, J. Appl. Crystallogr. 47 (2014) 1749-1754.

[24.] F. Könczöl, N. Farkas, T. Dergez, J. Belágyi, D. Lörinczy: Effect of tetracaine on model and erythrocyte membranes by DSC and EPR, J. of Thermal Anal. and Calorimetry 82 (2005) 201-206.

[25.] D. Marsh, A. Watts, P.F. Knowles: Cooperativity of the Phase Transition in Singleand Multibilayer Lipid Vesicles, Biochem. Biophys Acta 465 (1977.) 500-514.

[26.] M. Pantusa, R. Bartucci, L. Sportelli: Calorimetric and spin-label ESR studies of PEG:2000-DPPE containing DPPC/lyso-PPC mixtures, Colloid Polym. Sci. 285 (2007.) 649-656.

[27.] C. Grabielle-Madelmont, R. J. Perron: Calorimetric studies on phospholipid-water systems: I. dl-Dipalmitoylphosphatidylcholine (DPPC)—water system, Colloid Interf. Sci. 95 (1983) 471-482.

[28.] S.L. Schmid: Clathrin-coated vesicle formation and protein sorting: An integrated process, Annu. Rev. Biochem. 66 (1997) 511-548.

[29.] M. Wiener, S. White: Structure of a fluid dioleoylphosphatidylcholine bilayer determined by joint refinement of $\mathrm{x}$-ray and neutron diffraction data. III. Complete structure, Biophys J. 61 (1992) 434-447.

[30.] J.A. Bouwstra, G.S. Gooris, W. Bras, H. Talsma: Small angle X-ray scattering: possibilities and limitations in characterization of vesicles, Chem. Phys. Lipids 64 (1993) 83-98.

[31.] Z. Varga, Sz. Berényi, B. Szokol, L. Örfi, G. Kéri, I. Peták, A. Hoell, A. Bóta: A Closer Look at the Structure of Sterically Stabilized Liposomes: A Small-Angle X-ray Scattering Study, J. Phys. Chem. B. 114 (2010) 6850-6854.

[32.] G. Pabst, M. Rappolt, H. Amenitsch, P. Laggner: Structural information from multilamellar liposomes at full hydration: full q-range fitting with high-quality X-ray data, Phys. Rev. E 62 (2000) 4000-4009.

[33.] G. Pabst, R. Koschuch, B. Pozo-Navas, M. Rappolt, K. Lohner, P. Laggner: Structural analysis of weakly ordered membrane stacks, J. Appl. Crystallogr. 36 (2003) 1378-1388.

[34.] M.R. Brzustowicz, A.T. Brunger: X-ray scattering from unilamellar lipid vesicles, J. Appl. Crystallogr. 38 (2005) 126-131.

[35.] D. Chapman, V.B. Kamat, R.J. Levene: Infrared spectra and the chain organization of erythrocyte membranes, Science 160 (1968) 341-346.

[36.] A. Barth: Infrared spectroscopy of proteins, Biochim. Biophys. Acta 1761 (2007) 1073-1101. 
[37.] S. Berényi, J. Mihaly, S. Kristyan, L. Naszalyi-Nagy, J. Telegdi, A. Bota: Thermotropic and structural effects of poly(malic acid) on fully hydrated multilamellar DPPC-water systmes, Biochim. Biophys. Acta 1828 (2013) 661-669.

[38.] R.N.A.H. Lewis, R.N. McElhaney: Vibrational Spectroscopy of Lipids, in: Handbook of Vibrational Spectroscopy, JM Chalmers, P Griffiths (Eds), John Wiley \& Sons, 2001, pp. 3784-3801.

[39.] Z. Kóta, M. Debreczeny, B. Szalontai: Separable contributions of ordered and disordered lipid fatty acyl chian segments to $\mathrm{vCH}_{2}$ bands in model and biological membranes: a Fourier transform infrared spectroscopic study, Biospectroscopy, 5 (1999) 169-178.

[40.] T.L. Steck: The organization of proteins in the human red blood cell membrane, J.Cell Biol., 62 (1974.) 1-19.

[41.] A.D. Dupuy, D.M. Engelman: Protein area occupancy at the center of the red blood cell membrane, PNAS, 105 (2008.) 2848-2852.

[42.] R.A. Cooper, J.R. Durocher, M.H. Leslie: Decreased Fluidity of Red Cell Membrane Lipids in Abetalipoproteinemia, The J. of Clin. Investigation 60 (1977) 115-121.

[43.] J. Florin-Christensen, C.E. Suarez, M. Florin-Christensen, M. Wainszelbaum, W.C. Brown, T.F. McElwain, G.H. Palmer: A unique phospholipid organization in bovine erythrocyte membranes, PNAS 98 (2001) 7736-7741.

[44.] Ishida T, Ichihara M, Wang X, Yamamoto K, Kimura J, Majima E, Kiwada H: Injection of PEGylated liposomes in rats elicits PEG-specific IgM, which is responsible for rapid elimination of a second dose of PEGylated liposomes, J. Control Release. (2006); 112(1):15-25.

[45.] Wang X, Ishida T, Kiwada H: Anti-PEG IgM elicited by injection of liposomes is involved in the enhanced blood clearance of a subsequent dose of PEGylated liposomes, $\mathrm{J}$ Control Release. (2007) 4; 119(2):236-44. 


\section{Figures:}

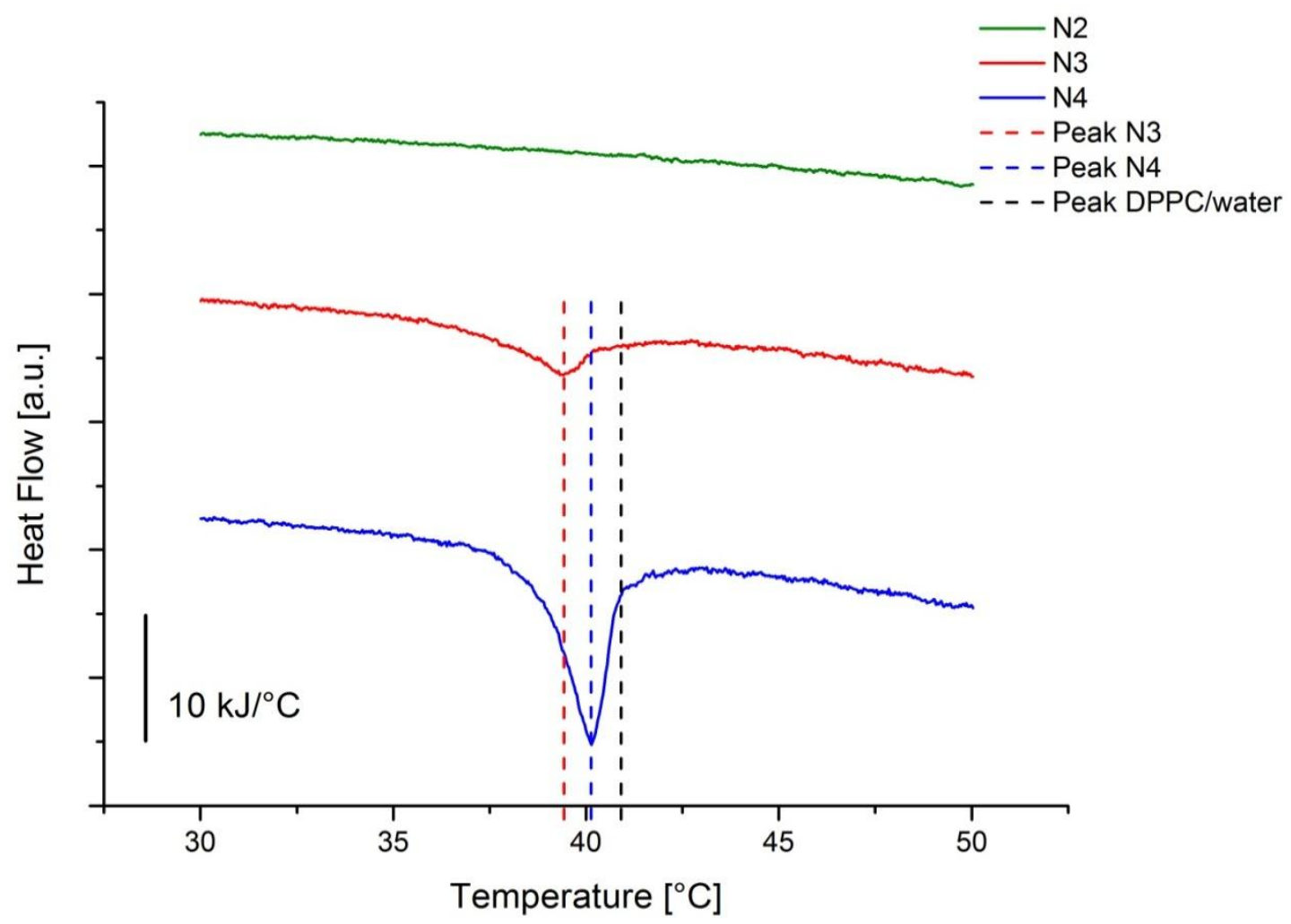

Figure 1: DSC curves of ghost membrane derived nanoerythrosome samples. N2: vesicles produced via sonication and extrusion, N3: vesicles via sonication and extrusion with additional DPPC, N4: vesicles via sonication, extrusion and with double amount of additional DPPC. Dotted lines signify the temperature values of the main phase transition peaks of N3, N4 and pure DPPC-water system. 

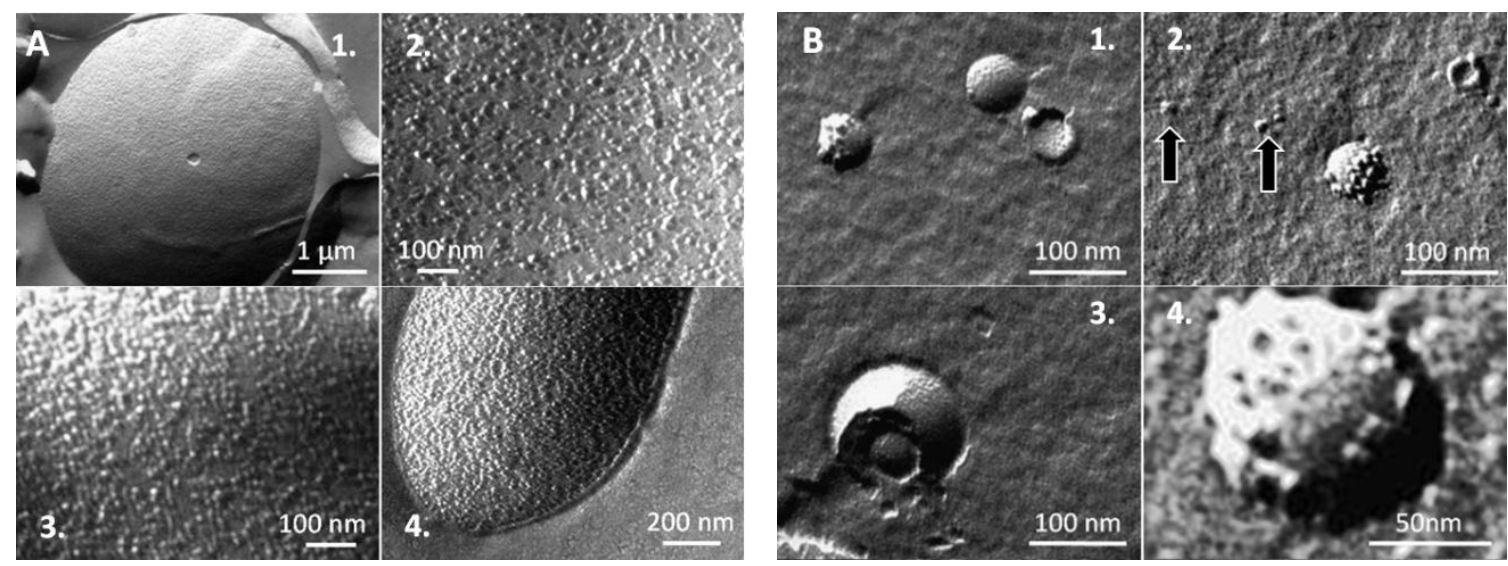

Figure 2: Electron microscopic images of different ghost membranes and nanoerythrosomes. Native protein rich ghost membrane (A) (1. large slice of ghost membrane, 2. „E face”, 3. „P face", 4. surface after etching); ultrasonic treated ghost membrane derived nanoerythrosomes and released proteins/protein aggregates marked by arrows (B) (1. uniform nanoerythrosomes, 2. proteins on the vesicle surface and out of the membrane, 3. multilamellar vesicle, 4. typical nanoerythrosome of N2 sample).
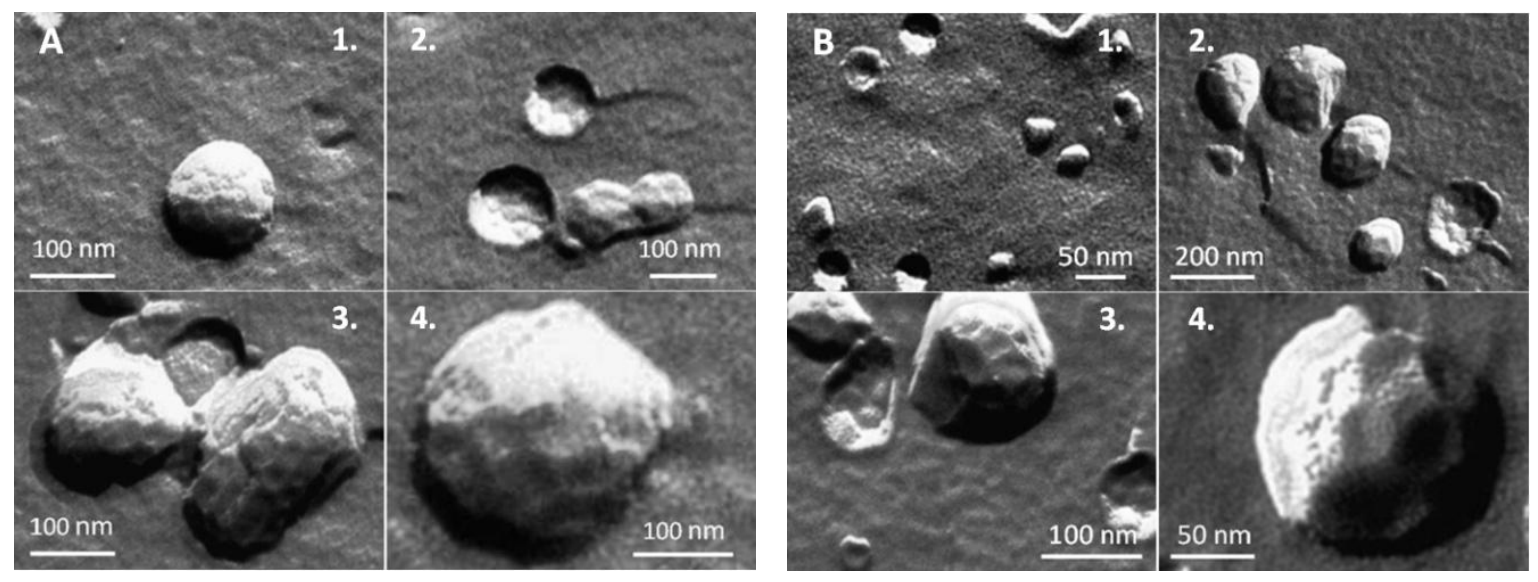

Figure 3: Electron microscopic images of nanoerythrosomes containing supplementary DPPC. The creations are frequently polyhedral. The ratio of extra lipid, relative to the lipid content of the original membrane is about $5 \times(\mathrm{A})$ (1. spherical vesicle, 2 . spherical and stuck-together vesicles, 3. multilamellar, aggregated membranes, 4. typical nanoerythrosome of the $\mathrm{N} 3$ sample); ratio is about $10 \times(\mathrm{B})$ (1. homogeneous size distribution, 2. nearly spherical vesicles, 3. different shapes, 4. typical nanoerythrosome of the N4 sample). 


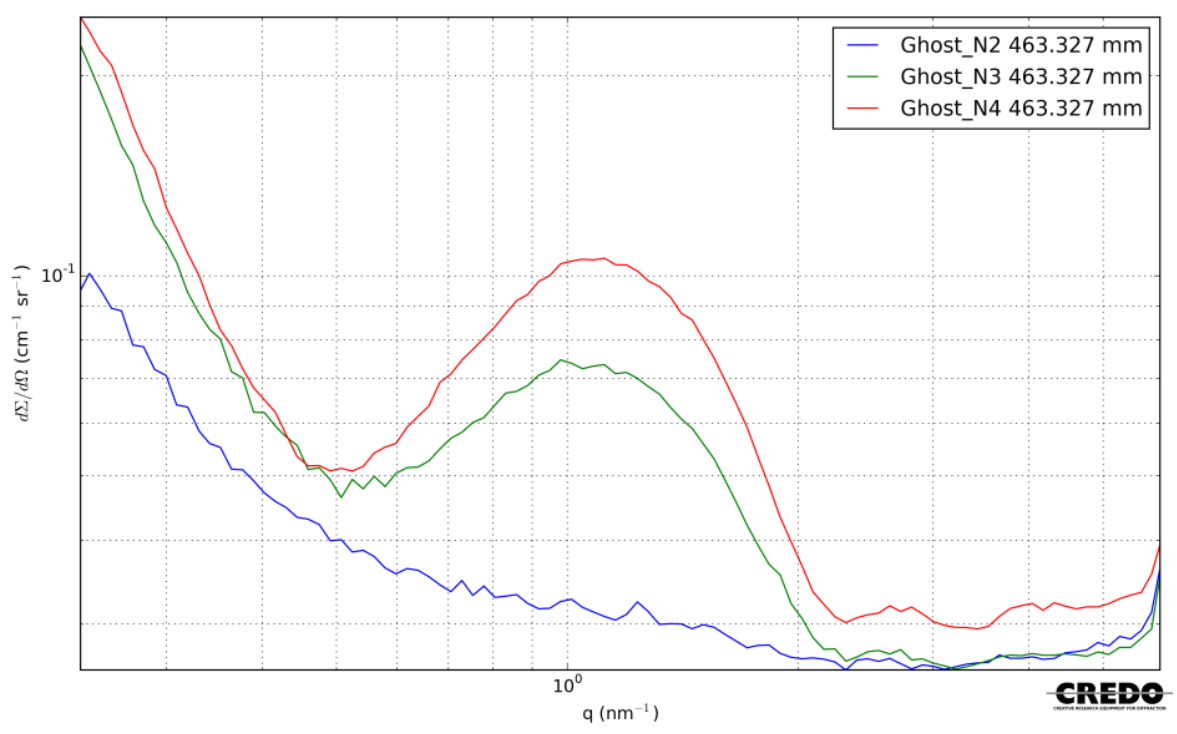

Figure 4: Small angle X-ray scattering images of the nanoerythrosome samples.

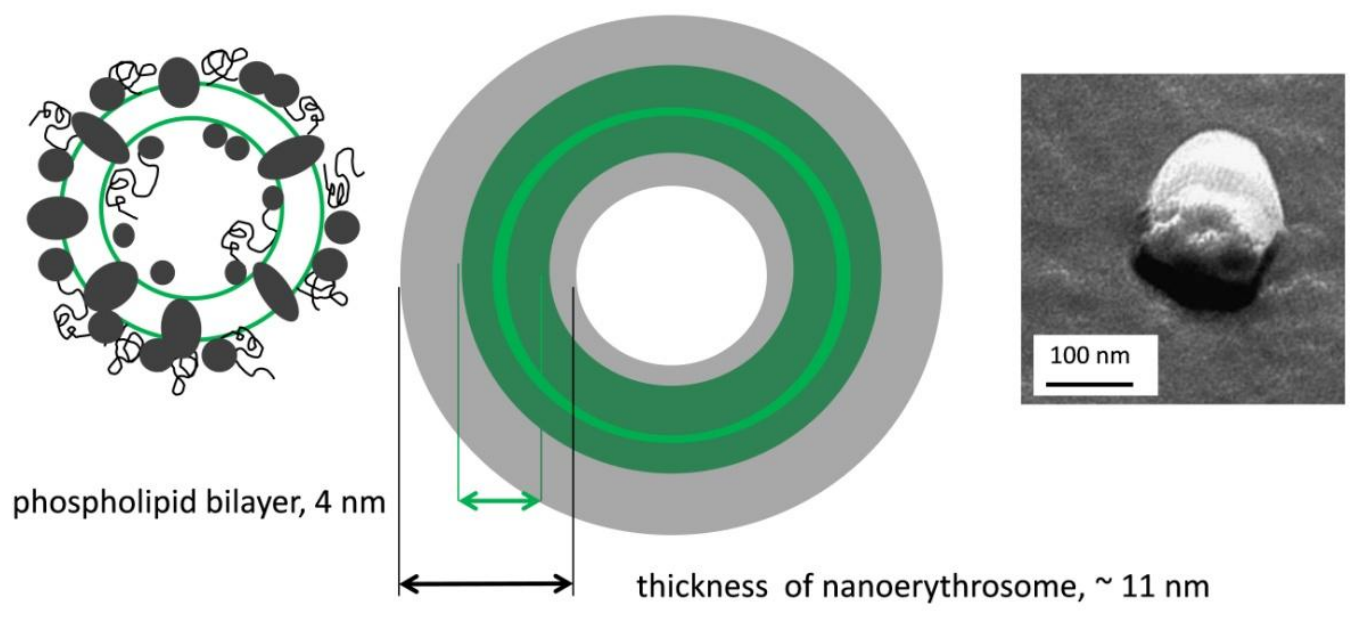

Figure 5: Shell model of the nanoerythrosomes for interpretation of the scattering data. A draft of the construction of the nanoerythrosome (left), asymmetrical $2 \mathrm{G}$ shell model used for calculation (middle), TEM image of a nanoerythrosome (right). 


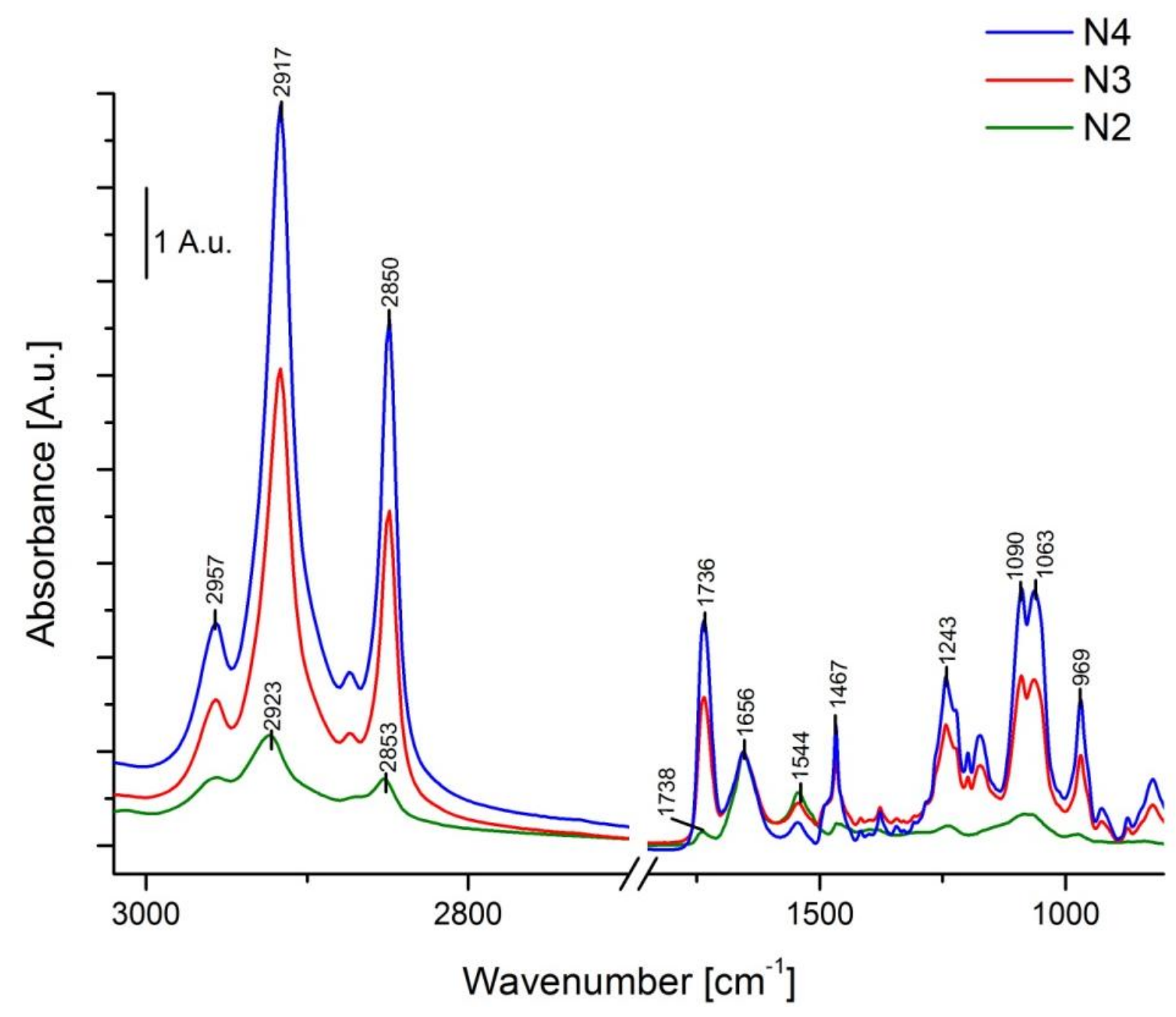

Figure 6: ATR FT-IR spectra of dry films of vesicle samples, prepared from ghost membrane: nanoerythrosome (N2), nanoerythrosome with additional DPPC (N3) and nanoerythrosome with double amount of DPPC (N4).

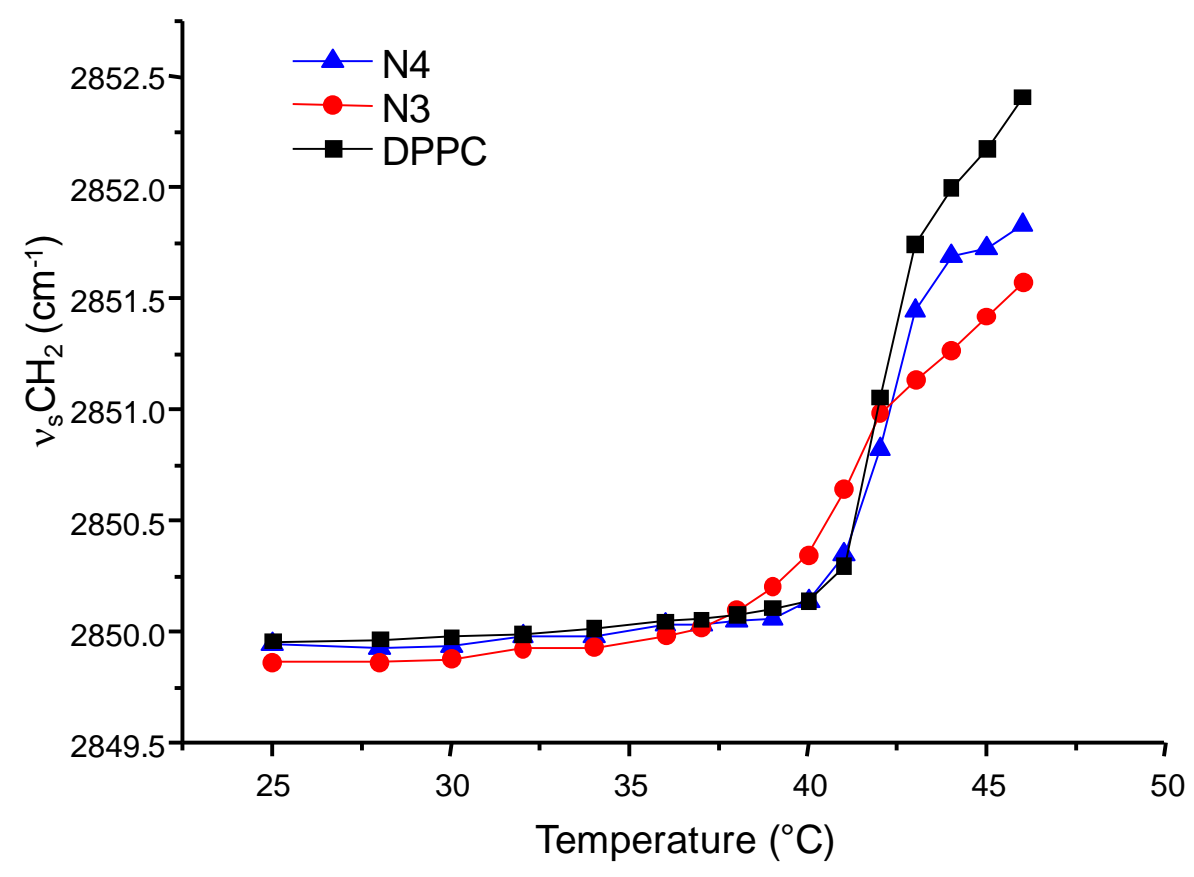


Figure 7: Thermotropic response curves of the symmetric stretching $\mathrm{CH}_{2}$ band for ghost derived nanoerythrosomes with DPPC content: N3 and N4. For comparison, the curve for pure DPPC liposome system is also shown.

\begin{tabular}{|c|c|c|c|}
\hline & \multicolumn{3}{|c|}{ P/L ratio } \\
& $\begin{array}{c}\text { Weight } \\
\text { measurement }\end{array}$ & $\begin{array}{c}\text { UV-VIS } \\
\text { spectroscopy }\end{array}$ & $\begin{array}{c}\text { FT-IR } \\
\text { A(Amide I)/A(CH2) }\end{array}$ \\
\cline { 2 - 4 } N2 & $1.12 \pm 0,1$ & $0.30 \pm 0.14$ & $0.59 \pm 0.13$ \\
N3 & $0.11 \pm 0,01$ & $0.04 \pm 0.02$ & $0.16 \pm 0.03$ \\
N4 & $0.05 \pm 0,01$ & $0.03 \pm 0.02$ & $0.04 \pm 0.03$ \\
\hline
\end{tabular}

Table 1. Protein/lipid ratios of nanoerythrosome vesicle samples determined by different methods 


\section{Supplementary:}

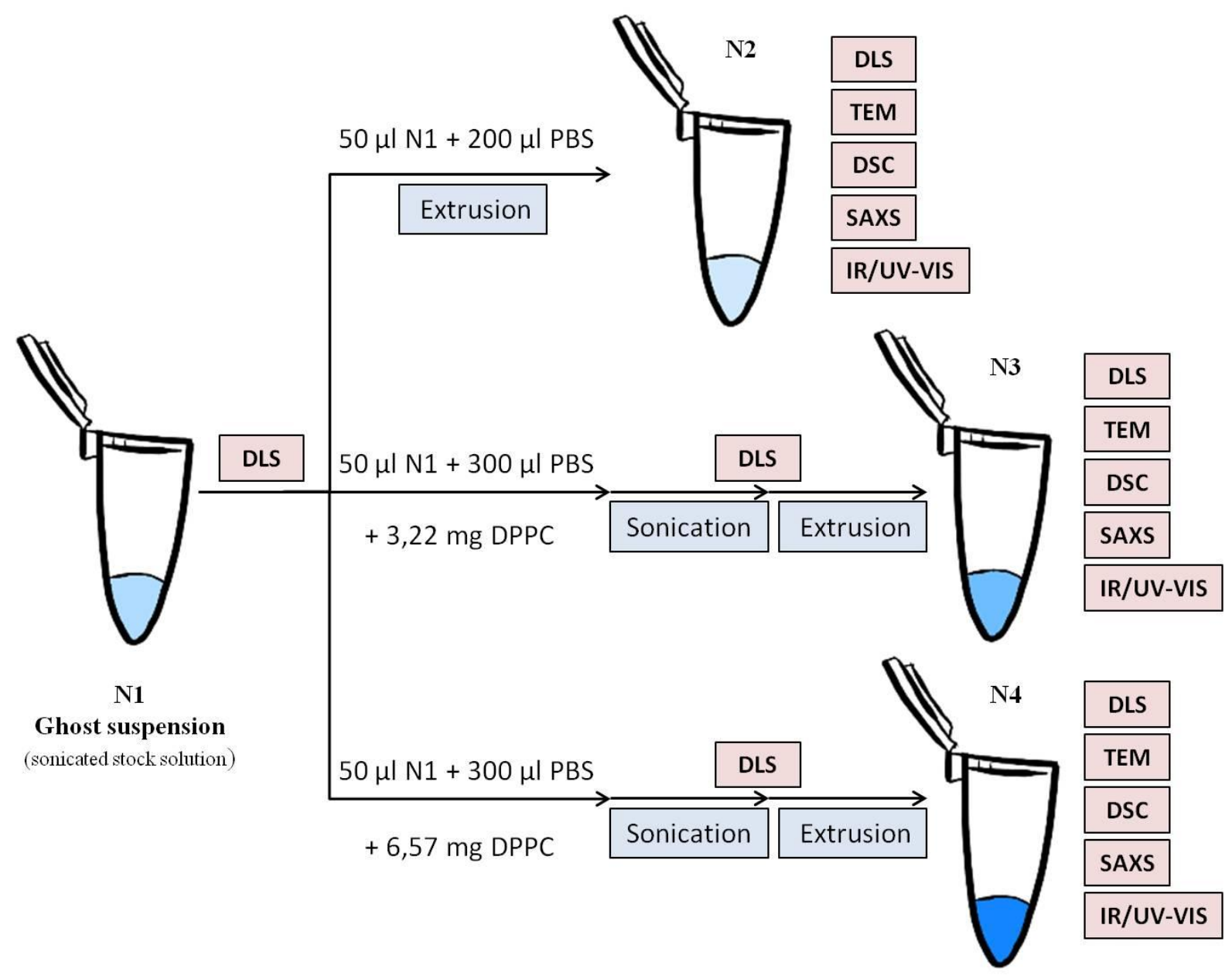

Supplementary 1: Protocol of nanoerythrosome preparation.

\begin{tabular}{|c||c||c|}
\hline & $\begin{array}{c}\text { Average diameter } \\
{[\mathrm{nm}]}\end{array}$ & $\begin{array}{c}\text { Zeta potential } \\
{[\mathrm{mV}]}\end{array}$ \\
\hline \hline N2 & $135 \pm 75$ & $-42 \pm 8.2$ \\
N3 & $213 \pm 167$ & $-29 \pm 5.1$ \\
N4 & $217 \pm 161$ & $-22 \pm 5.8$ \\
\hline
\end{tabular}

Supplementary 2: The average size and size distribution on DLS, and Zeta potential data of nanoerythrosome samples. 

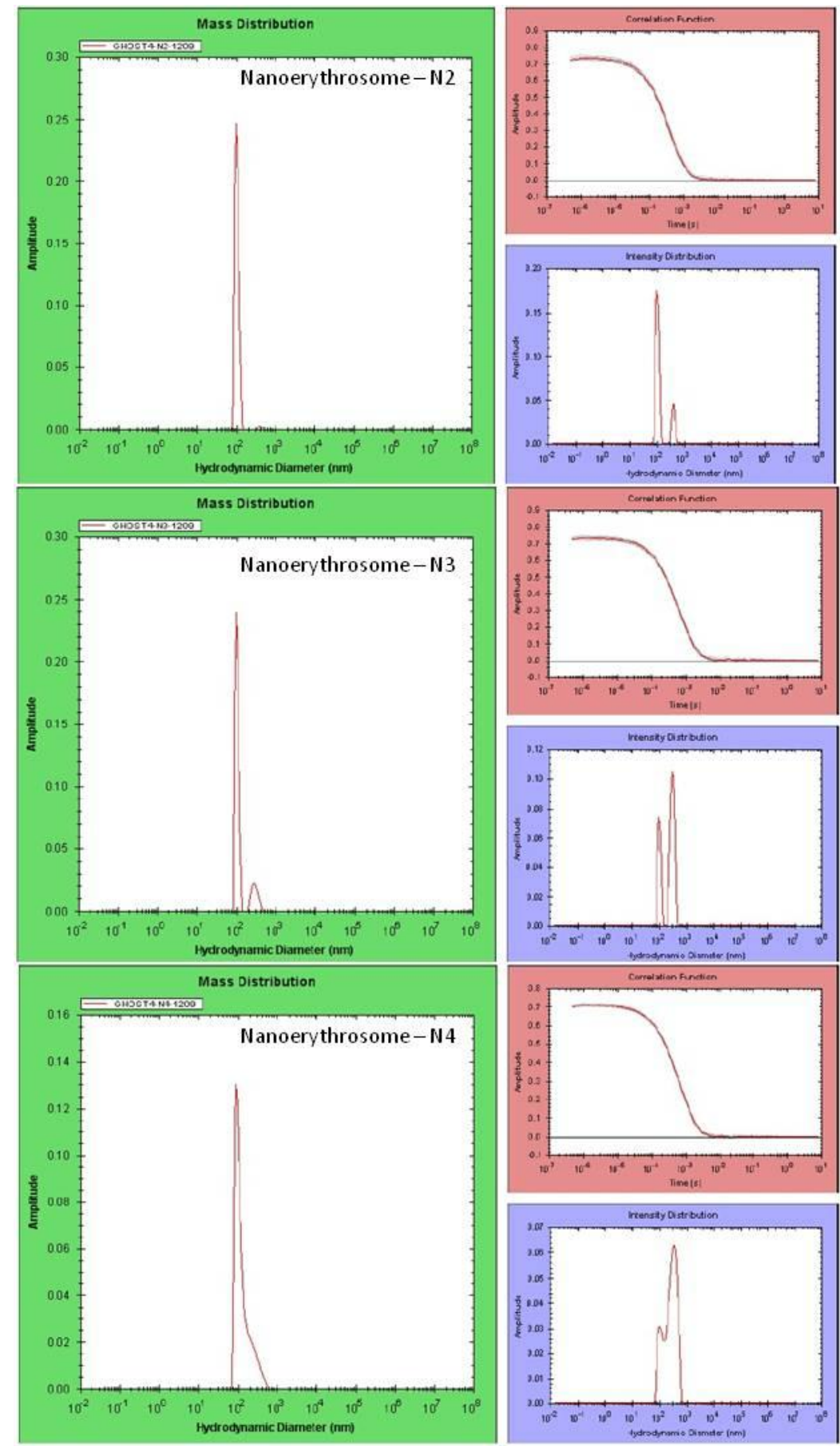

Supplementary 3: Original DLS report diagrams of nanoerythrosome samples. 

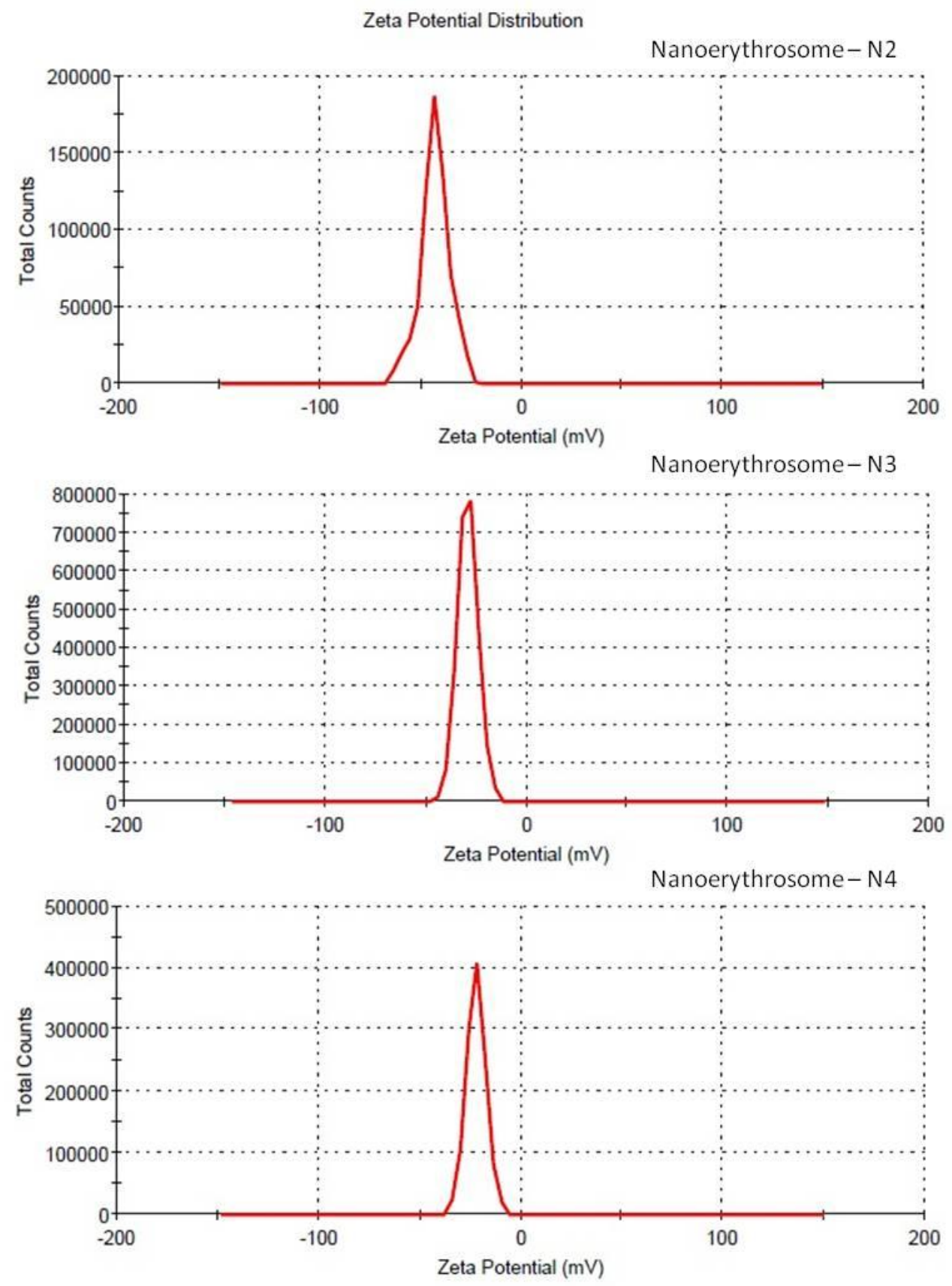

Supplementary 4: Original zeta potential report diagrams of nanoerythrosome samples. 


\begin{tabular}{|c||c|c|c|c|}
\hline & $\mathrm{N} 2$ & $\mathrm{~N} 3$ & $\mathrm{~N} 4$ & $\mathrm{DPPC}$ \\
\hline \hline $\mathrm{T}_{\mathrm{m}}\left[{ }^{\circ} \mathrm{C}\right]\left( \pm 0,1{ }^{\circ} \mathrm{C}\right)$ & - & 39.5 & 40.1 & 41 \\
$\Delta \mathrm{T}\left[{ }^{\circ} \mathrm{C}\right]$ & - & 2.5 & 1.7 & 0.4 \\
$\Delta \mathrm{H}[\mathrm{kJ} / \mathrm{mol}$ lipid $]$ & - & $3.7 \pm 1,2$ & $9.7 \pm 1,5$ & $37 \pm 3$ \\
\hline
\end{tabular}

Supplementary 5: DSC peak values and enthalpy changes of main phase transitions in different nanoerythrosomes (N2, N3, N4) calculated from curves Fig.1. compared to pure DPPC liposomes.

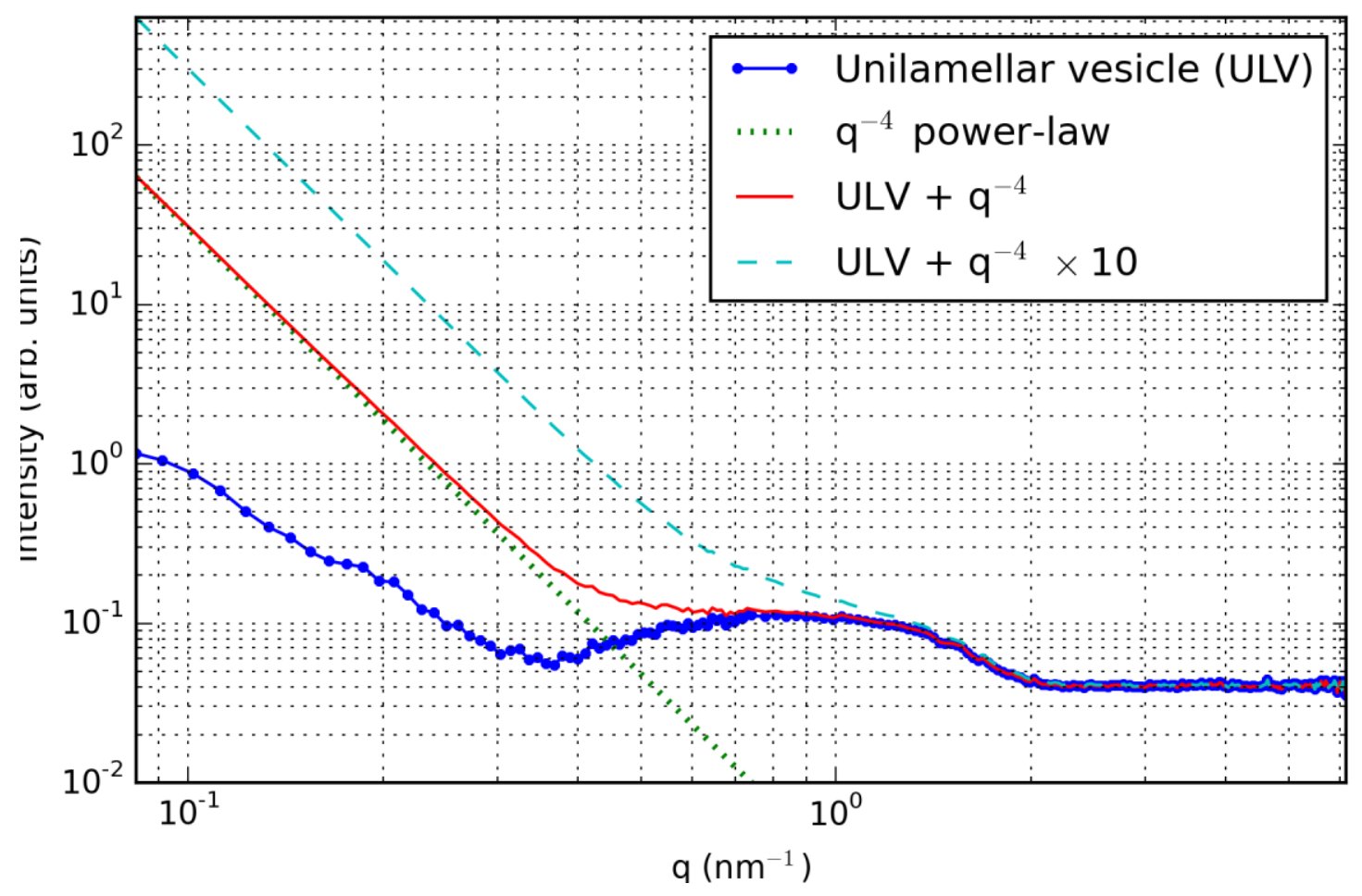

Supplementary 6: Synthesis of a scattering curve resembling that of sample N2 from a measured scattering of a sample of unilamellar vesicles and a $q^{-4}$ power-law contribution. 


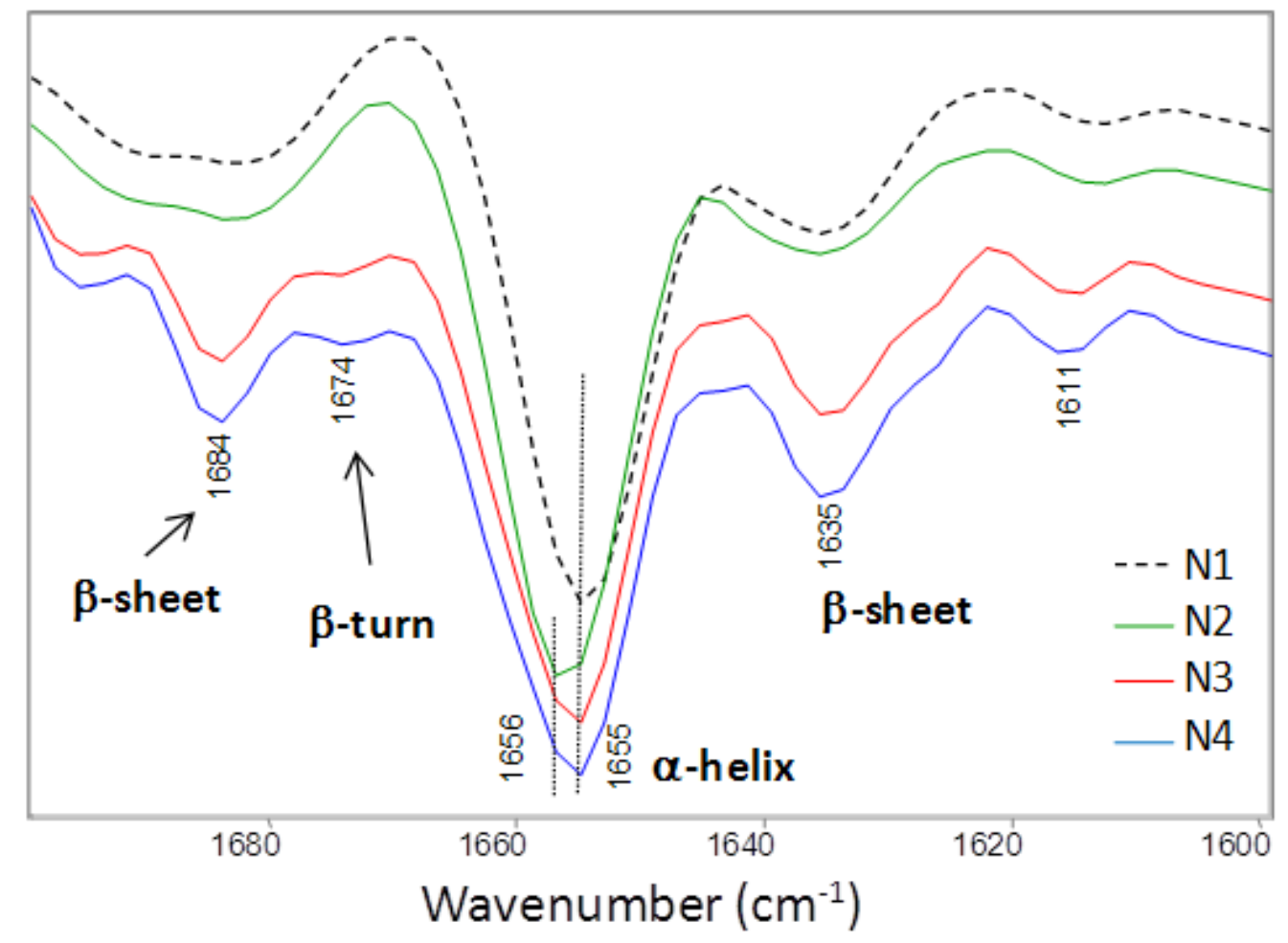

Supplementary 7: Protein secondary structure assessed by second derivative IR spectra. From bottom to top: native ghost membrane N1, nanoerythrosomes $\mathrm{N} 2$ (after sonication and extrusion) and nanoerythrosomes with additional DPPC N3 and N4.

\begin{tabular}{|c|c|c|}
\hline \multicolumn{3}{|c|}{ Concentration values (UV-VIS) } \\
\cline { 2 - 3 } N2 & Protein content $[\mathrm{mg} / \mathrm{ml}]$ & Lipid content $[\mathrm{mg} / \mathrm{ml}]$ \\
\cline { 2 - 3 } & $0.79 \pm 0.05$ & $2.65 \pm 0.37$ \\
N3 & $0.72 \pm 0.06$ & $16.50 \pm 3.01$ \\
N4 & $0.58 \pm 0.05$ & $20.70 \pm 2.10$ \\
\hline
\end{tabular}

Supplementary 8: Protein and lipid concentrations of nanoerythrosome samples. 